DOI: $10.14451 / 1.169 .123$

\title{
НАЦИОНАЛЬНЫЕ ИННОВАЦИОННЫЕ СИСТЕМЫ В УСЛОВИЯХ ГЛОБАЛЬНОЙ КОНКУРЕНЦИИ (НА ПРИМЕРЕ ГЕРМАНИИ)
}

\author{
(c) 2018 Зарицкий Борис Ефимович \\ доктор исторических наук, профессор кафедры мировой экономики \\ Московский государственный институт международных отношений (университет) \\ Министерства иностранных дел Российской Федерации (МГИМО) \\ 119454, г. Москва, пр-т Вернадского, 76 \\ E-mail:borsar@mail.ru
}

Цель статьи - проанализироать сильные и слабые стороны инновационной системы Германии, ее место в группе европейских и мировых инновационных лидеров. Особое внимание автор уделил рассмотрению приоритетных направлений современной стратегии ФРГ в сфере высоких технологий, форм и методов стимулирования государством инновационной активности в компаниях и в исследовательских центрах. Проведенное исследование позволило сделать вывод о том, что главные усилия немецкого правительства и бизнеса направлены на то, чтобы сохранить и упрочить конкурентные преимущества Германии в качестве одного из мировых лидеров в произволстве промышленной продукции и в экспорте. Именно на это напрвлены стратегия «Индустрия 4.0», «Национальная индустриальная стратегия 2030», программы внедрения цифровых технологий, ускоренного развития искусственного интеллекта.

Ключевые слова: инновационная политика, технологические изменения, научные исследования, корпоративный сектор, государственная поддержка, венчурный капитал, инвестиционная активность, налоговые льготы.

Германия уверенно удерживает свои позиции в группе мировых инновационных лидеров. В межстрановых сопоставлениях она не занимает призовых мест, но стабильно входит в первую «десятку». Так, в европейском рейтинге European Innovation Scoreboard 2018 она заняла 7-е место, а в глобальном рейтинге The Global Innovation Index - 9-е место среди 126 стран (табл. 1).

К преимуществам инновационной системы ФРГ обычно относят высокий уровень инвестиций в НИОКР в корпоративном секторе, значительное количество инновационных компаний, активную поддержку государством научных разработок в исследовательских центрах и в университетах, большая численность специалистов с высшим образованием и научными степенями.

К слабостям - слабо развитый рынок венчурного капитала, низкий уровень доходов от продажи патентов и лицензий за рубеж, «недружественную среду» для появления инновационных стартапов, дефицит высококвалифицированных кадров в сфере информационных технологий, недостаточный уровень инновационной активности на малых и средних предприятиях.

Велики и региональные различия инновационной активности. В двух землях, Баден-Вюртемберге и Баварии, расходы на НИОКР составляют более $45 \%$ всех затрат на эти цели по стране в целом, а в Сааре - только $0,6 \%$, в Саксонии-Анхальт - 0,9\% [1]. В большинстве рейтин-

Таблица 1. Мировые инновационные лидеры.

\begin{tabular}{|l|l|}
\hline \multicolumn{1}{|c|}{ European Innovation Scoreboard 2018 } & \multicolumn{1}{c|}{ The Global Innovation Index 2018} \\
\hline 1. Швеция & 1. Швейцария \\
2. Дания & 2. Швеция \\
3. Финляндия & 3. Нидерланды \\
4. Нидерланды & 4. США \\
5. Великобритания & 5. Великобритания \\
6. Люксембург & 6. Дания \\
7. Германия & 7. Сингапур \\
8. Бельгия & 8. Финляндия \\
9. Ирландия & 9. Германия \\
10. Австрия & 10. Ирландия \\
\hline
\end{tabular}

Источник. [5,8] 
гов малые страны Северной Европы (Швеция, Дания, Финляндия) по совокупности показателей качества инновационной системы, как правило, опережают Германию.

За последние десять лет в Германии было сделано немало, чтобы упрочить позиции страны в международной конкуренции. Совокупные расходы на НИОКР за этот период в текущих ценах почти удвоились, а их доля в ВВП увеличилась с 2,43\% в 2005 г. до почти 3\% в 2017 г.(табл.2.). Таким образом, была достигнута планка, установленная в свое время для стран Евросоюза в Лиссабонской стратегии. По этому показателю Германия входит в «пятерку» европейских лидеров, а среди стран ОЭСР занимает 8-е место. Впереди Южная Корея, Израиль, Япония, Швейцария, страны Северной Европы, но крупнейшие экономики Евросоюза имеют показатели существенно хуже немецких: во Франции расходы на НИОКР составляют $2,2 \%$ ВВП, в Италии- $1,3 \%$ ВВП, в Испании $-1,2 \%$ ВВП.

Структура источников финансирования НИОКР в Германии в целом соответствует современным тенденциям: 65\% инвестиций в научные исследования и разработки обеспечивают частные компании, около 30\% приходится на федеральные, земельные и местные бюджеты, оставшиеся $5 \%$ - это вклад иностранных компаний и дотации из фондов ЕС. Государство занимается финансированием исследовательской работы, прежде всего в университетах и научных центрах. Доля бюджетных средств, выделяемых на поддержку НИОКР в частном секторе, крайне незначительна и составляет всего 3,4\% от общей суммы, что почти в два раза меньше среднего показателя по ОЭСР (6,6\%). Основная часть этих денег идет на стимулирование инновационной активности малых и средних предприятий (МСП), которые покрывают за счет поддержки государства $16-17 \%$ своих расходов на НИОКР [4].

О приоритетах государственной политики в инновационной сфере можно судить по характеру отраслевого распределения средств федерального бюджета, предназначенных на поддержку НИОКР. 18 млрд. евро, выделенные на эти цели в 2017 г., были распределены следую- щим образом [3]:

- медицина и здравоохранение - 2,5 млрд. евро

- поддержка инновационной активности МСП - 1,97 млрд. евро

- авиастроение и космос $-1,8$ млрд. евро

- энергетика - 1,56млрд. евро

- охрана окружающей среды - 1,44 млрд. евро

- общественные и экономические науки 1,2 млрд. евро

- информатика и телекоммуникации $-1,18$ млрд. евро

- оборона -1,09 млрд. евро

- информатика и телекоммуникации $-1,18$ млрд. евро

- нанотехнологии и новые материалы $-0,7$ млрд. евро

- инновации в образовании - 0,6 млрд. евро

Распределение расходов на НИОКР в частном секторе имеет свои особенности.

Во-первых, здесь давно существует явный перекос в пользу базовых отраслей обрабатывающей промышленности со средним уровнем наукоемкости (в диапазоне от 3 до 9\% доли НИОКР в обороте). В наиболее высокотехнологичных «верхних этажах» (свыше 9\% в обороте) концентрация ресурсов существенно отстает от главных конкурентов.

Во-вторых, львиная доля расходов на НИОКР (более 30\%) приходится на автомобилестроение. Без вклада этой отрасли в наукоемкое производство и экспорт Германия бы вообще «выпала» из списка мировых технологических лидеров. Такая почти монокультурная специализация делает положение Германии весьма уязвимым, особенно с учетом того факта, что активность автомобильных компаний все больше переносится за рубеж.

B-третьих, несмотря на государственную поддержку, вклад МСП в инновационную активность корпоративного сектора остается весьма скромным. Только 40\% предприятий с числом занятых до 250 человек эксперты с оговорками относят к разряду инновационных. При этом большая часть из них попадает в категорию «имитаторов», т.е. их деятельность по обнов-

Таблица 2. Динамика расходов на НИОКР в ФРГ (\% ВВП)

\begin{tabular}{|c|c|c|c|c|c|}
\hline 1995 & 2000 & 2005 & 2010 & 2015 & 2017 \\
\hline 2,19 & 2,40 & 2,43 & 2,72 & 2,91 & 3,0 \\
\hline
\end{tabular}

Источник. [4] 
лению продукции сводится главным образом к незначительным конструктивным усовершенствованиям и, как правило, имеет мало общего с реализацией принципиально новых технологических решений.

В Германии сегодня, как и раньше, основная доля расходов на НИОКР в корпоративном секторе приходится на крупные и крупнейшие компании с количеством занятых более 500 человек. В промышленности они покрывают 87\% инвестиций на научные исследования и разработки.

Достаточно посмотреть на перечень первых десяти мировых и немецких концернов с самыми большими бюджетами расходов на НИОКР, чтобы заметить уязвимые места в отраслевом распределении инновационной активности в корпоративном секторе ФРГ. Так, в глобальный список топ-10 вошли шесть американских и только одна немецкая компания. По профилю 9 из 10 представленных фирм относятся либо к сектору ИТК, либо к фармацевтической отрасли.
Единственная немецкая компания - это автомобильный концерн Volkswagen (табл.3).

В национальном списке лидеров в масштабах Германии на три автомобильных концерна Volkswagen, Daimler и BMW - приходится более половины инвестиций в НИОКР. Из 10 представленных немецких компаний только три (Bayer, SAP и Merck) можно отнести к инновационным компаниям «верхнего этажа» хай-тека. Наконец, бюджеты на НИОКР всех представленных немецких компаний, за исключением Volkswagen, значительно уступают бюджетам мировых лидеров (табл.4).

Одним из критериев эффективности научно-исследовательской и инновационной деятельности является число зарегистрированных патентов и публикаций в высокорейтинговых журналах. В 2017 г. в Европейское патентное ведомство (ЕПВ) было подано в общей сложности свыше 160 тыс. заявок на регистрацию патентов европейскими и неевропейскими компа-

Таблица 3. Мировые инновационные лидеры

\begin{tabular}{|l|c|c|}
\hline \multicolumn{1}{|c|}{ Компания } & $\begin{array}{c}\text { Расходы на НИОКР } \\
\text { (млрд. долл.) }\end{array}$ & Доля НИОКР в обороте (\%) \\
\hline 1. Amazon (США) & 16,1 & 11,8 \\
\hline 2. Alphabet (США) & 13,9 & 21,5 \\
\hline 3. Intel (США) & 12,7 & 21,5 \\
\hline 4. Samsung(Р.К.) & 12,7 & 5,3 \\
\hline 5. Volkswagen (ФРГ) & 12,2 & 14,1 \\
\hline 6. Microsoft (США) & 12,0 & 21,9 \\
\hline 7. Roche (Швейцария) & 11,4 & 25,4 \\
\hline 8. Merck\&Со (США) & 10,1 & 4,7 \\
\hline 9. Apple (США) & 10,0 & 19,4 \\
\hline 10. Novartis (Швейцария) & 9,6 & \\
\hline
\end{tabular}

Таблица 4. Инновационные лидеры Германии

\begin{tabular}{|l|c|c|}
\hline \multicolumn{1}{|c|}{ Компании } & Расходы на НИОКР (млрд.долл.) & Доля НИОКР в обороте (\%) \\
\hline 1. Volkswagen & 12,2 & 5,3 \\
\hline 2. Daimler & 6,9 & 4,2 \\
\hline 3. Siemens & 5,5 & 6,2 \\
\hline 4. Bayer & 4,9 & 10,0 \\
\hline 5. BMW & 4,5 & 4,6 \\
\hline 6. SAP & 3,2 & 7,8 \\
\hline 7. Continental & 3,0 & 13,1 \\
\hline 8. Merck & 2,1 & 3,2 \\
\hline 9. BASF & 2,0 & 1,4 \\
\hline 10. Dt.Telekom & 1,1 & \\
\hline
\end{tabular}

Источник. [13] 
ниями. Американские фирмы с долей $26 \%$ сохранили свое лидерство, немцы заняли второе место (15\%), японцы- третье (13\%). Китайские компании с долей 5\% поднялись на пятое место. (табл.5). Примечательно, что в «десятку» лидеров по количеству патентных заявок вошли только две немецкие компании - Siemens и Robert Bosch, а в top-25 - еще два хорошо известных бренда - BASF и Bayer [6]. Фактически список немецких корпораций, лидирующих по количеству зарегистрированных патентов, не меняется десятилетиями. Это крупнейшие концерны из четырех традиционных отраслей, определяющих лицо германской экономики - автомобилестроение, машиностроение, электротехника и химическая отрасль.

Эту закономерность подтверждают и отчеты Всемирной организации интеллектуальной собственности (ВОИС), которая публикует данные о количестве поступивших патентных заявок по процедуре РСТ (Договор о патентной кооперации), что может обеспечить заявителю охрану его изобретения в 152 государствах-участниках Международной патентной системы, в то время как участниками Европейской патентной организации являются только 38 стран. По этой методике Германия по количеству поданных патентных заявок в последние годы переместилась с третьего на четвертое место, пропустив вперед не только США и Япония, но и Китай. В списке компаний-лидеров, помимо уже упоминавшихся Siemens, Bosch и BASF, тоже хорошо знакомые Daimler, BMW, Volkswagen, Audi, химические гиганты Henkel, Linde, крупнейший в Европе производитель бытовой электротехники BSH Hausgeraete, один из ведущих в мире производителей светотехнической продукции Osram и т.д.[12]. Иными словами, все это снова преимущественно компании «среднего этажа» хай-тека.

По количеству зарегистрированных патен- тов в расчете на 1 млн. жителей Германия опережает США, Францию, Великобританию, но уступает Японии, Швейцарии, Швеции, Финляндии. В итоге - пятое место.

По количеству научных публикаций доля Германии по сравнению с 2005 г. сократилась с 6 до 4,5\% в 2017 г. Такая же судьба постигла большинство стран Западной Европы, США и Японию. Главная причина - резкое увеличение числа публикаций исследователей из Китая, Южной Кореи и Индии. Однако по качественным характеристикам публикаций (международный престиж журналов, в которых были опубликованы статьи, количество цитирований и ссылок на них) ученые из развитых стран по-прежнему заметно опережают своих коллег из азиатских государств.

Одной из слабостей инновационной системы ФРГ, по общему мнению экспертов, является неразвитость рынка венчурного капитала, объемы которого оцениваются в 0,027\% ВВП (рисунок 1). Это один из самых низких показателей в континентальной Европе, не говоря уже о Соединенных Штатах и Великобритании. Венчурный капитал в качестве инструмента финансирования особенно важен для стартапов, не имеющих, как правило, ни кредитной истории, ни залогового обеспечения для получения банковского кредита. К тому же на Немецкой бирже (Deutsche Boerse) вплоть до последнего времени не было специального сегмента для молодых и небольших по размеру компаний инновационного типа. Выход на биржу таких компаний в Германии скорее исключение, чем правило. В большинстве случаев это закрывает перед ними перспективу финансирования за счет привлечения акционерного капитала. В свою очередь, венчурные фонды лишены привычной для них схемы работы, когда первоначальные инвестиции в перспективные молодые компании вкла-

Таблица 5. Страны-лидеры по количеству патентных заявок

\begin{tabular}{|c|c|}
\hline По системе ЕРО & По системе РСТ \\
\hline $\begin{array}{l}\text { 1. США - 26\% } \\
\text { 2. ФРГ - } \mathbf{1 5 \%} \\
\text { 3. Япония - } 13 \% \\
\text { 4. Франция -6\% } \\
\text { 5. КНР - 5\% } \\
\text { 6. Швейцария }-4 \% \\
\text { 7. Нидерланды - 4\% } \\
\text { 8. Респ. Корея - 4\% } \\
\text { 9. Великобритания - 3\% } \\
\text { 10. Италия -3\% }\end{array}$ & $\begin{array}{l}\text { 1. США -26,3\% } \\
\text { 2. Япония -20,3\% } \\
\text { 3. КНР -13,7\% } \\
\text { 4. ФРГ - 8,3\% } \\
\text { 5. Респ.Корея - 6,7\% } \\
\text { 6. Франция - 3,9\% } \\
\text { 7. Великобритания - 2,4\% } \\
\text { 8. Нидерланды - 2,1\% } \\
\text { 9. Швейцария - 2,0\% } \\
\text { 10. Швеция - 1,7\% }\end{array}$ \\
\hline
\end{tabular}

Источник. [6,12]. 


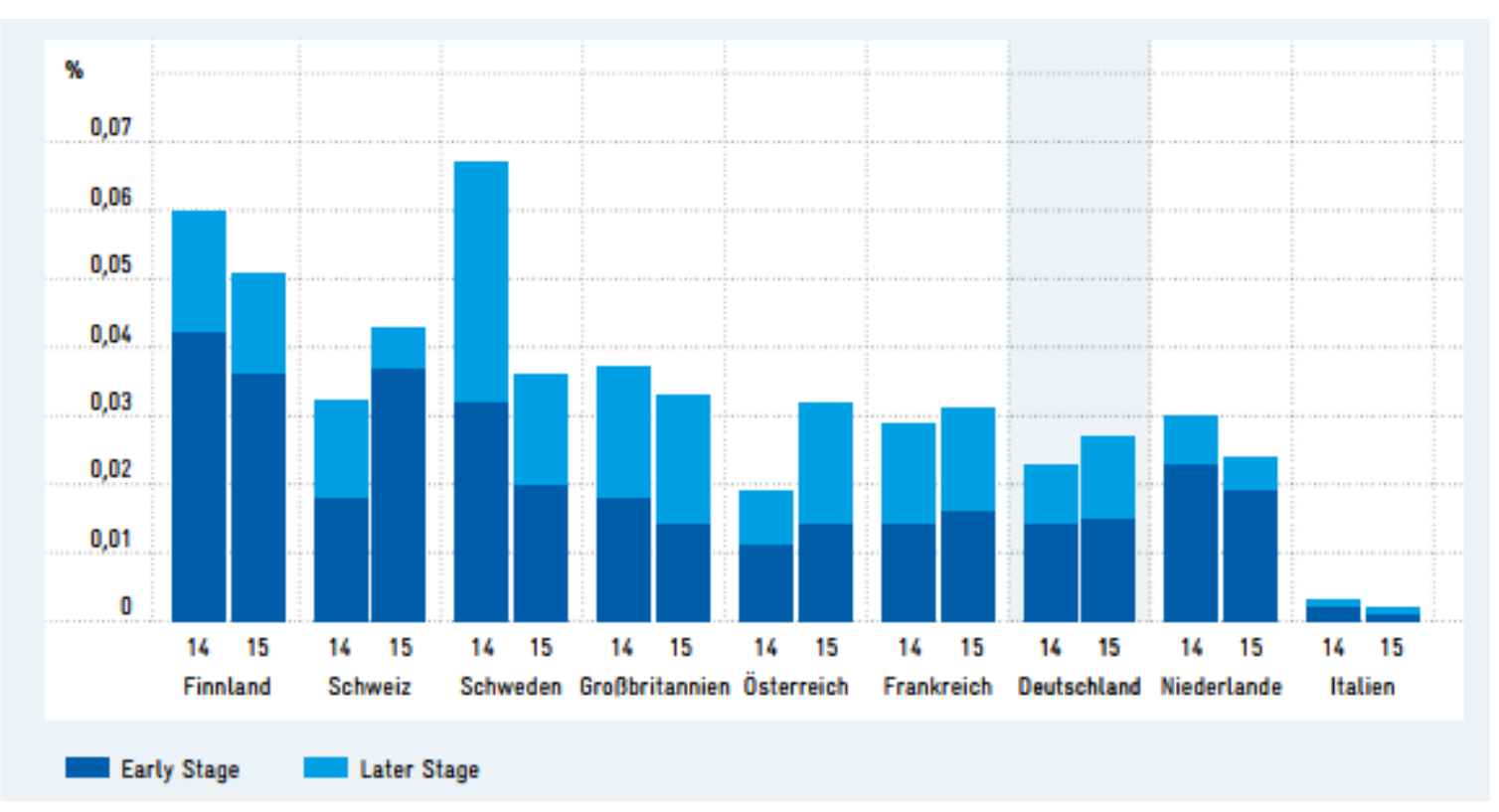

Рис.1. Доля венчурного капитала в ВВП (2014-2015 гг.)

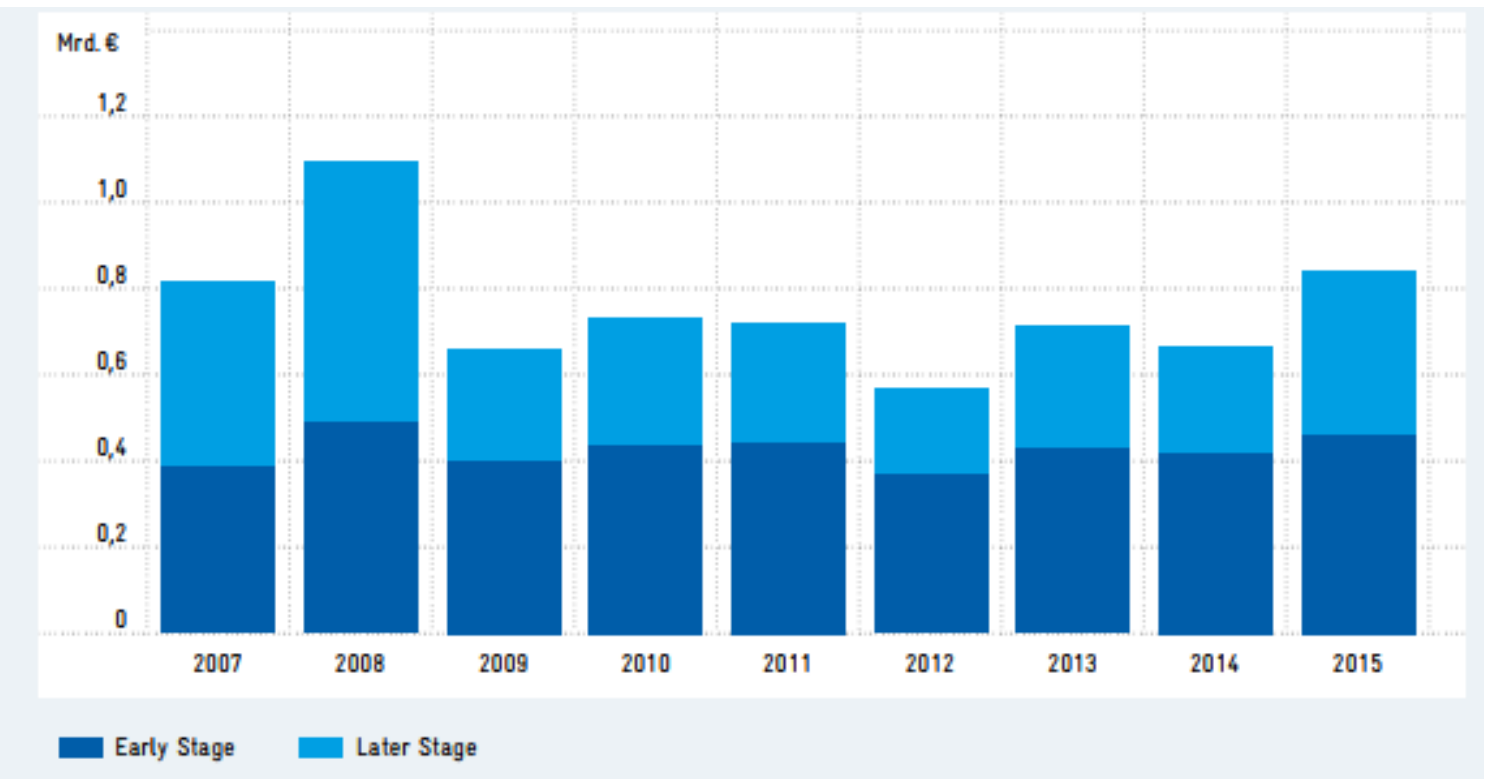

Puc. 2. Венчурный капитал в Германии (млрд. евро) Источник. [7].

дывают в расчете на быстрый рост их биржевой капитализации.

В ежегодном докладе экспертной группы правительству ФРГ о положении дел в инновационной сфере проблемам стартапов был посвящен отдельный раздел [7]. Там подчеркивалось, в частности, что из-за дефицита финансирования развитие инновационного бизнеса в Германии происходит медленнее, чем в ряде европейских стран (рисунок 2). Многие стартапы изначально предпочитают регистрироваться в США или Ве- ликобритании, где рынок венчурного капитала развит лучше. Но даже созданные в Германии перспективные стартапы на ранних стадиях роста часто перекупают иностранные компании или инвестфонды, и технологии уходят за рубеж.

Федеральное правительство пытается за счет бюджета компенсировать нехватку венчурного капитала. В июле 2016 г. было объявлено о создании фонда (Tech-Growth-Fund), из которого на каждый вложенный евро начинающие предприниматели смогут получить один евро 
в форме кредита на льготных условиях. В январе 2017 г. принята федеральная программа INVEST-2.0, в рамках которой инвесторы в инновационные стартапы смогут получить от государства ссуду в размере до 100 тыс. евро. В 2015 г. государственный банк развития Kreditanstalt fur Wiederauaufbau (KfW) заявил о готовности выступить в роли пайщика немецких венчурных фондов и вложить в расширение их капитальной базы 400 млн. евро.

Эксперты считают все эти меры полезными, но недостаточными, поскольку в целом рамочные условия для создания нового бизнеса в Германии остаются неблагоприятными. Достаточно сказать, что в рейтинге Doing Business 2017 Германия по критерию «Начать бизнес» получила скандальную оценку - 114-е место из 190 обследованных стран. Практически по всем основным составляющим показателям (количество административных барьеров, время, необходимое на регистрацию собственности, стоимость преодоления всех бюрократических процедур, необходимый размер стартового капитала и т.д.) оценки оказались хуже, чем в 2010 г., когда Германия заняла тоже отнюдь не призовое 84-е место.

Таким образом, реальные условия создания нового бизнеса в Германии сильно отличаются от той благостной картины, которую обычно пытаются представить официальные власти на разнообразных презентациях. Даже при скептическом отношении к международным рейтингам, методика составления которых подчас вызывает обоснованные вопросы, разница в позиционировании Германии и ее многочисленных конкурентов настолько бросается в глаза, что впору задуматься о причинах". Чтобы реализовать амбициозную правительственную программу «Hi-Tech Strategy 2020», в которой, в частности, ставится задача довести расходы на НИОКР до 3,5\% ВВП и удвоить объем венчурного капитала в стране, считают немецкие эксперты, необходимо, как минимум изменить методы стимулирования инновационной активности на предприятиях и политику в сфере государственных закупок.

Что касается методов поддержки НИОКР, то тема эта для Германии не новая и дискуссии по этому поводу ведутся не первый день [1]. Дело в том, что государственное финансирование на проведение научных исследований на предпри- ятиях выделяется только под конкретные проекты, а механизм налоговых льгот не используется вообще. Мотивируют это обычно тем, что таким образом государство концентрирует средства на наиболее перспективных или общественно значимых проектах. На практике же деньги часто достаются либо наиболее энергичным лоббистам, либо приходят со значительным опозданием, либо вообще расходуются впустую, поскольку государственные чиновники далеко не всегда в состоянии определить, какие именно научные направления и конкретные проекты являются действительно перспективными.

Между тем, в большинстве стран ОЭСР налоговое стимулирование НИОКР зарекомендовало себя куда более эффективным методом поощрения инновационной активности на предприятиях, чем выборочное финансирование государством отдельных проектов. Так, например, размер налоговых льгот, привязанных к расходам на НИОКР, составляет в США 0,7\% ВВП, в Японии $-1,4 \%$, в Южной Корее $-1,9 \%$, в Нидерландах и Австрии - 1,7\%, во Франции - 2,7\%, в Ирландии - 2,9\% ВВП [7]. Налоговое стимулирование НИОКР особенно значимую роль играет для малых и средних предприятий. В Европе этот метод не используется только в Швеции и Швейцарии.

Что касается политики в сфере государственных закупок, то она активно используется в ряде стран как мера, стимулирующая спрос на инновации и продвижение их на рынок. Очевидно, что риск для производителей инновационной продукции выше, чем для производителей традиционной. Значительную долю этих рисков составляет непредсказуемость спроса на инновационную продукции. Потребительское поведение не всегда удается правильно предсказать. В связи с этим инноватор рискует не получить ожидаемую прибыль или даже остаться с отрицательным сальдо. Не во всех случаях инновации ведут к удешевлению продукции, что порой лишает инноваторов конкурентного преимущества по цене. Спрос на инновационную продукцию зачастую вытесняется более дешевой и привычной в использовании. На фазе продвижения новой продукции, когда рынок оказывается к ней не восприимчив, функцию поддержки могут взять на себя государственные органы, заинтересованные в продвижении инноваций.

\footnotetext{
* В том же рейтинге Doing Business 2017 по той же позиции «Начать бизнес» Ирландия заняла 10-е место, Швеция-15-е, Великобритания-16-е, Нидерланды-22-е, Франция-27-е, Финляндия-28-е.
} 
В Германии рынок государственных закупок составляет около 15\% ВВП. В абсолютных цифрах это весьма внушительная сумма- от 350 до 400 млрд. евро. Сколько из этих денег расходуется на поддержку инновационных продуктов и услуг, никто точно сказать не берется. В Германии действует децентрализованная система госзакупок, в которую вовлечены не только многочисленные федеральные и земельные министерства и ведомства, но и сотни государственных учреждений и структур различного уровня с собственными бюджетами и представлениями о приоритетных направлениях их использования. Однако нетрудно подсчитать, что один процент от совокупных расходов на госзакупки, потраченный на поддержку инноваторов в промышленности и в сфере услуг, составляет 3,5-4 млрд. евро, что больше той суммы, которая выделяется из бюджета на стимулирование НИОКР на предприятиях.

По экспертным оценкам, при целенаправленной переориентации госзакупок на поддержку инноваций можно было бы $12-15 \%$ средств от общей суммы направить на эти цели. Министерство экономики ФРГ признает, что сегодня политика госзакупок во многом носит инерционный характер и инновационная составляющая в ней просматривается слабо. В 2013 г. было принято решение о создании межведомственного координационного центра (KOINNO), который начал действовать с 1 января 2017 г. В его задачу входит консалтинг и координация политики госзакупок всех государственных ведомств и учреждений федерального, земельного и местного уровней с упором на поддержку инновационной активности прежде всего малых и средних предприятий [4]. Насколько эта мера изменит общую картину, пока судить трудно. Но важен уже сам по себе тот факт, что политика госзакупок с опозданием, но признана важным инструментом поддержки инноваций.

Оценивая в целом инновационный потенциал страны, эксперты трех ведущих исследовательских центров Германии в аналитическом докладе Innovationsindikator 2017, подготовленном по заказу Федерального союза немецкой промышленности (BDI), делают такой вывод: «На первый взгляд инновационная система Германии выглядит хорошо. Но мы не можем чувствовать себя уверенно пока на главном направлении, которое будет определять нашу конкурентоспособность - движение к цифровой экономике, нас опережают Соединенные Штаты, Великобритания и ряд других стран... Нас не должны успокаивать ни улучшение хозяйственной конъюнктуры, ни достижения нашего экспорта, ни низкая безработица. Быстрота и радикальный характер технологических изменений могут обесценить все рецепты, которые обеспечивали нам успех в прошлом» [9].

По совокупности оценочных критериев достигнутого уровня дигитализации, т.е. цифровой трансмиссии информационных данных, в производственном секторе, в сфере услуг, органах государственного управления, системе образования и т.д. Германия заняла в рейтинге Innovationsindikator 17-е место. Впереди США, Великобритания, Финляндия, Швейцария, Нидерланды, Израиль, Южная Корея, Австралия, Сингапур. Эти оценки не оспаривают и в правительстве [11].

Чтобы ликвидировать уязвимые места в инновационной системе страны, эксперты предлагают программу, которая включает следующие основные положения [4,7,9]:

- поднять к 2025 г. уровень расходов на НИОКР с нынешних 3-х до 3,5\% ВВП;

- увеличить за пять лет объем венчурного капитала с 0,027 до 0,06\% ВВП;

- удвоить за этот же срок размеры государственной поддержки цифровой трансформации экономики;

- создать эффективную модель электронного правительства и других звеньев государственного управления;

- ввести налоговое стимулирование инновационной активности на предприятиях;

- добиться большей отраслевой диверсификации научных исследований, которые сегодня сконцентрированы преимущественно в нескольких традиционных секторах промышленности;

- активно использовать имеющиеся резервы, чтобы смягчить дефицит высококвалифицированной рабочей силы: стимулировать приток женщин в науку, производство, сферу услуг; задействовать специалистов пенсионного возраста; ликвидировать барьеры для использования иностранных специалистов; создать условия для обучения востребованным специальностям беженцев;

- ввести в ВУЗах на факультетах с инженерной специализацией междисциплинарные курсы, нацеленные на то, чтобы прививать у 
студентов практические навыки по созданию собственного бизнеса;

- воспитывать «грюндерский дух» у молодежи на всех этапах обучения, начиная со школьной скамьи

Насколько эти рекомендации адекватны серьезности назревших проблем, судить преждевременно. Германия, где ядро экономики составляет обрабатывающая промышленность, может сохранить свои позиции в группе мировых лидеров только за счет глубокой модернизации своей индустрии с ориентацией на высокотехнологичные сектора, в которых конкурентоспособность конечного продукта будет определяться его новизной и уникальностью, а не стоимостью рабочей силы и энергоресурсов. Не только в экспертном сообществе, но и в правительстве ФРГ есть понимание, что, несмотря на ускоренное развитие исследовательских работ в области многих ключевых технологий таких как: Интернет вещей, искусственный ин- теллект, робототехника, страна отстает от США, Японии и Китая в их коммерциализации и практическом освоении [11]. Теперь уже и Еврокомиссия признает, что не только Германия, но и Евросоюз в целом упустил многие возможности, связанные с цифровыми инновациями, и проигрывает в темпах обновления своего предпринимательства ближайшим конкурентам [2, С.105].

В феврале 2019 г.министр экономики ФРГ П. Альтмайер выступил с инициативой разработки новой национальной индустриальной стратегии [10]. В представленных им тезисах он наряду с констатацией серьезных проблем в инновационной сфере сформулировал ряд вопросов, которые ставят и отечественные эксперты и ответы, на которые исключительно важны для выработки и реализации инновационной политики в нашей стране. Главный из них: что и как может сделать государство для поддержки, стимулирования и распространения инновационных преобразований в современной экономике?

\section{Библиографический список}

1. Хайретдинова Э.М, Зубенко В.А. Источники и формы финансирования инновационной деятельности в Германии//Мир новой экономики, 2018, Т.12. Вып.1, С.124-131

2. Циренщиков В.С. Инновационное обновление экономики Евросоюза////Современная Европа, 2018 , № 4. C.101-111

3. Ausgaben des Bundes fuer Wissenschaft, Forschung und Entwicklung 2018 - URL: file:///C:/Users/user/Downloads/ BuFI-5\%20(2).pdf

4. Bundesbericht Forschung und Innovationen 2018 - URL: https://www.bmbf.de/pub/Bufi_2018_Hauptband.pdf

5. European Innovation Scoreboard 2018 - URL: file://C:/Users/user/Downloads/ETAY18001ENN_version1812018. pdf

6. EPO Annual Report 2017 - URL: https://www.epo.org/about-us/annual-reports-statistics/annual-report/2017. html

7. Gutachten zu Forschung, Innovation und technologischer Leistungsfaehigkeit Deutschlands 2018 - URL: https:// www.e-fi.de/fileadmin/Gutachten_2018/EFI_Gutachten_2018.pdf

8. Global Innovation Index 2018 - URL: https://www.wipo.int/edocs/pubdocs/en/wipo_pub_gii_2018.pda

9. Innovaton Indicator 2017 - URL: https:/www.isi.fraunhofer.de/en/presse/2017/presseinfo-19-2017innovationsindikator.html

10. Nationale Industriestrategie 2030 - URL: https:/www.bmwi.de/Redaktion/DE/Publikationen/Industrie/ nationale-industriestrategie-2030.html

11. Monitoring Report Wirtschaft Digital 2018 - URL: https://www.bmwi.de/Redaktion/DE/Publikationen/ DigitaleWelt/monitoring-report-wirtschaft-digital-2018-kurzfassung.html

12. Patent Cooperation Treaty Yearly Review 2017 - URL: https://www.wipo.int/publications/en/details.jsp?id=4196

13. Wirtschaft forscht//Handelsblatt, 2017, Oktober 24 